\title{
Cellular Neurothekeoma
}

National Cancer Institute

\section{Source}

National Cancer Institute. Cellular Neurothekeoma. NCI Thesaurus. Code C156278.

A neurothekeoma with increased cellularity. 